\title{
Selecting Estimating Software: Perspectives from the Construction Industry
}

\section{Dr. Charles McIntyre, Indiana University-Purdue University of Indianapolis}

Charles McIntyre is a Professor and Program Director of the Construction Engineering Management Technology Program at Indiana University Purdue University Indianapolis (IUPUI). He received a Ph.D. from Penn State in 1996. Prior to joining IUPUI, he was a faculty member and former chair in the Department of Construction Management and Engineering at North Dakota State University in Fargo. Dr. McIntyre's current research includes sustainable construction, green building, and industry-academic collaborations. He is an active member of the American Society for Engineering Education and the American Council for Construction Education. Dr. McIntyre has served on the ASEE Board of Directors and is an ASEE Fellow.

Dr. Sanjeev Adhikari, Indiana University-Purdue University of Indianapolis Mr. Veto Matthew Ray, Indiana University-Purdue University of Indianapolis

Mr. Matt Ray is the director for the Facilities Management Technology graduate program as well as a lecturer for the Construction Engineering Management Technology Program offered through the Purdue School of Engineering and Technology at Indian University Purdue University Indianapolis. He currently provides instruction for Facilities Planning and Management, Introduction to Facilities Engineering Systems, Financial Aspects of Facilities Management and Construction Cost and Bidding. He is a graduate of Purdue School of Engineering and Technology receiving degrees in Construction Technology, Architectural Technology and a Masters in Facility Management. His field experience includes residential and light commercial construction. He has been an architectural designer as well as superintendent for single and multi-family residential construction projects. Mr. Ray worked as an engineering design manager in the Building Components Manufacturing Industry for over fifteen years.

\section{Mr. James W. White, Indiana University-Purdue University of Indianapolis}

J. William White AIA is a senior lecturer with the Construction Engineering Management Technology program within the Purdue School of Engineering and Technology in Indianapolis. He is a registered architect who has more than 25 years of varied construction industry experience. Mr. White has undergraduate degrees from Indiana University and Ball State University and a masters degree from Purdue University Indianapolis. He is an active member of the American Institute of Architects and the Construction Specifi- cations Institute. 


\section{Selecting Estimating Software Perspectives of an Industry Advisory Board}

\section{Introduction}

Virtually all construction companies use some form of software to complete construction quantity take-offs and cost estimates. The array of available software is quite extensive [1]. The available software poses several challenges for their selection, installation, and use.

Construction firms must consider several variables and the stakes are very high as these tools can fundamentally change how a company does business, which directly affects the bottom line [2] [3]. In order to stay current with the industry, academic institutions must follow the industry's lead by adopting current and relevant software and integrating these technologies into the curriculum. Thus, academia faces the same software selection challenges as does industry [4].

The fundamental dilemma is to determine specific criteria that must be considered during the software selection process. For example, construction firms may select estimating software based on cost, features, functions, reviews, recommendations, operating systems, and compatibility with their current estimating procedures. The research described in this paper used a survey to determine the importance of a number of software selection criteria. The survey was sent to the Industry Advisory Board (IAB) of the Construction Engineering Management (CEMT) program at Indiana University Purdue University Indianapolis (IUPUI). The IAB represents all facets of the construction industry in the greater Indianapolis area. Since most of the CEMT students seek employment in central Indiana, it seemed reasonable to survey the local construction industry for their perspectives on quantity take-off and estimating software. The survey was designed to not only determine the type of software systems used, but to determine the relative importance and the ranking of the various criteria used during the software selection process [5].

The ultimate goal of this project is to develop a "decision matrix" that could be used by the CEMT program to assist in the selection of quantity take-off and estimating software. Analysis of the survey data led to the development of the matrix which was designed to be adaptable for use in the industry as well as academia. In addition, the matrix has a measure of expandability for use in other types of software selection. This paper documents the results of this research and the development of the fully functional decision matrix.

\section{Background}

There is a myriad of software applications that are designed exclusively for the construction industry. They address every aspect of the construction process including graphic production, rendering, 3D simulation, quantity take-off, estimating, scheduling, and comprehensive project management. As is typical of any computer-based application these construction-specific products vary considerably by a seemingly endless array of variables, such as cost, sophistication, complexity, and interoperability to name just a few.

Partly in response to this variability, a given construction company may acquire multiple titles to accomplish similar tasks. One company may possess different estimating software applications. 
Determining which application is utilized for a given project may be driven by client preference, project size, construction complexity, CAD documentation, or even team preference. For example, Software A does one function significantly better than Software B, although Software $\mathrm{B}$ is superior in other ways, in which case both may used, although in different ways.

The use of estimation software is well established in the industry for good reason. Karshenas and Tse observed that estimating software is helpful to both predict construction project productivity using historical database management information and to assist in keeping records of productivity information of completed projects [6]. In another study, Yang et al. analyzed 112 projects from the "Chinese software project benchmarking dataset" and conducted a survey of 116 organizations to investigate cost estimate software. The results of their survey indicated that large projects were more prone to cost and schedule overruns and that most computing managers and professionals were neither satisfied nor dissatisfied with the project estimation [7].

As educators within a construction management program and for the construction industry that we serve, this vast software universe poses a challenge. We want our classroom content to align with the industry that our students will soon be entering. Selecting software applications from all that is available is problematic. Similar to our counterparts in the industry, educators must select software which satisfies a number of often competing requirements. Our software acquisitions must compliment the curriculum, integrate with the technical capacity of the institution, and provide sufficient challenge to students, all the while reflecting current industry standards. We are thus presented with a shared dilemma: how do both educators and industry decide which software application(s) to acquire?

Software acquisition and adaptation decisions often involve comparing alternatives of several criteria. However, the end users of the software systems may not necessarily be familiar with the overall decision-making criteria. To address this problem, Reinhartz-Berger et al. proposed an approach for comparing software functionality from the view point of the user. This approach employed ontological concepts to define functionality in terms of system behaviors. Their results demonstrated not only that the ontological approach is usable after a brief training period but it also provided results comparable to ranking done by expert software developers [8].

The challenge therefore demands more than simply asking the construction industry "what software do you use?" Given the complexity of the construction industry and variety of construction situations, the responses will be varied and multifaceted to such a degree that the results would be difficult to interpret. In order to address this at its core, one must consider the problem in greater detail, first considering all the variables that play a role in the decisionmaking process while also recognizing that some criteria are clearly more important than others.

This task is the subject of significant study. Jayakumar and Abran reviewed software test estimation techniques and considered some of the challenges that needed to be overcome if the foundations of these software testing estimation techniques are to be improved [9]. Moløkken$\emptyset$ stvold et al. produced an overview of the estimation methods that software companies apply to estimate their own projects, why those methods are chosen, and how accurate they are. They surveyed 18 different companies and project managers of 52 different projects. The authors found that 1) average effort overruns are $41 \%$; $)$ the estimation performance has not changed 
much over the past 10-20 years; 3) expert estimation remains the dominating estimation method; 4) estimation accuracy is not significantly impacted by using formal estimation models, and 5) software managers tend to believe that the estimation accuracy of their own company is better than packaged programs [10].

One cannot consider the assessment of software without considering its context, specifically the construction industry. Authors Goulding and Lou conducted a two-part study that researched the readiness of construction industry firms to adopt new technology. In their preliminary remarks, they cited work by Lou and Alshawi that noted the construction industry is uniquely challenged to the adoption of new technologies for a number of reasons, including: the industry's structure; the fragmented supply chain; the lack of investment in information and communication technology (ICT); limited ICT support systems; and limited support and empowerment of senior decision makers [11].

In their results, Goulding and Lou observed eight (8) "technology factor enablers" that the 40 industry participants within their study identified as most important in evaluating technology for adoption. In order of most important to least important, they identified the following:
1. Sharability / Interoperability
2. Information management
3. Technology transfer \& diffusion
4. Reliability \& support
5. Connectivity \& security
6. Technology investments
7. Infrastructure (hardware)
8. Use / Trial of new technologies

The authors postulated that these results "...demonstrate the perception that e-readiness within construction is not purely driven by technology per se, but more by its people and processes..." The authors ultimately concluded that their overall results demonstrated "...that e-readiness within the construction sector was still in its infancy." Even so, they were encouraged by the fact that the construction industry appeared to be embracing the importance of "...e-readiness assessment tools to help shape this transition" [11].

What is needed is a decision-making tool that possesses sufficient flexibility to be useful to both the construction industry and the academic programs that support the industry. The tool must be responsive to this data and incorporate the variables that are identified as important by the construction industry while simultaneously allowing sufficient customization to address individual circumstances, regardless of whether the user is a construction professional or a student within an academic program. 


\section{Methodology}

The methodology used in this research involved an electronic survey of local construction firms that are on the CEMT IAB at IUPUI. The survey was designed to not only determine the type of estimating software systems used, but to ask fundamental questions associated with software selection. This study utilized a survey to rate and rank the selection criteria for the decisionmaking process related to software selection process. The survey was produced and distributed using Qualtrics [12].

The Qualtrics survey had four sections: business, quantity take-off and cost estimating software products, software selection strategies, and ranking software selection criteria. There was a total of 21 questions on the survey. From the 21 questions, 4 questions were related to business; 4 questions were related to type of software product used to quantity take-off and cost estimating; 12 questions were related to software selection strategies; and 1 question was related to ranking software selection criteria. Prior to survey distribution, the questions were reviewed by the CEMT IAB with limited revisions. After minor revisions, the survey was distributed to 55 CEMT IAB members. After the initial email, two reminders were sent over a period of three weeks at which point the survey was closed.

\section{Data Analysis}

Nineteen (19) industry members responded for a response rate of approximately $35 \%$. As shown in Table 1, eleven responses were from commercial businesses, three responses were from industrial businesses, three responses were from heavy highway, and two responses were from others (professional societies and trade associations).

\begin{tabular}{|r|c|c|c|c|}
\hline \multicolumn{5}{|c|}{ Table 1 - Primary Business of Survey Respondants } \\
\hline Survey \# & (1) Business & $\begin{array}{c}\text { (2) \# of } \\
\text { Employees }\end{array}$ & (3) Gross Revenues & $\begin{array}{c}\text { (4) \# of } \\
\text { Estimators }\end{array}$ \\
\hline 19 & Commercial & $<25$ & $<10,000,000$ & $<5$ \\
\hline $\mathbf{1}$ & Commercial & $50-100$ & $10,000,000-50,000,000$ & $<5$ \\
\hline $\mathbf{2}$ & Commercial & $50-100$ & $10,000,000-50,000,000$ & $<5$ \\
\hline $\mathbf{9}$ & Commercial & $50-100$ & $10,000,000-50,000,000$ & $10-15$ \\
\hline 16 & Commercial & $100-200$ & $50,000,000-100,000,000$ & $<5$ \\
\hline 15 & Commercial & $100-200$ & $>100,000,000$ & $<5$ \\
\hline $\mathbf{4}$ & Commercial & $100-200$ & $>100,000,000$ & $5-10$ \\
\hline 14 & Commercial & $100-200$ & $>100,000,000$ & $5-10$ \\
\hline $\mathbf{6}$ & Commercial & $100-200$ & $>100,000,000$ & $10-15$ \\
\hline $\mathbf{8}$ & Commercial & $>200$ & $>100,000,000$ & $>15$ \\
\hline 11 & Commercial & $>200$ & $>100,000,000$ & $>15$ \\
\hline $\mathbf{7}$ & Industrial & $>200$ & $10,000,000-50,000,000$ & $<5$ \\
\hline 13 & Industrial & $>200$ & $>100,000,000$ & $10-15$ \\
\hline $\mathbf{5}$ & Industrial & $>200$ & $>100,000,000$ & $>15$ \\
\hline $\mathbf{1 0}$ & Heavy Highway & $>200$ & $>100,000,000$ & $>15$ \\
\hline $\mathbf{1 2}$ & Heavy Highway & $>200$ & $>100,000,000$ & $>15$ \\
\hline $\mathbf{1 7}$ & Heavy Highway & $>200$ & $>100,000,000$ & $>15$ \\
\hline $\mathbf{1 8}$ & Other & $>200$ & $>100,000,000$ & $<5$ \\
\hline $\mathbf{3}$ & Other & $>200$ & $>100,000,000$ & $5-10$ \\
\hline
\end{tabular}


Upon completion of the survey the following data was gathered, sorted, and analyzed to gain insight on the survey population, industry software, and the importance of specific criteria for software selection. Ultimately this data was utilized to direct the development of a decision matrix tool for selecting software that could be used by industry and academic programs. Table 1 depicts the business corresponding to the 19 survey respondents, which includes type of business, number of employees, gross revenues and number of estimators.

Figure 1 represents the breakdown of respondents within the three major areas of construction with a smaller population identified as other. As shown in the figure, commercial construction companies comprised the majority of respondents, which included 11 of the 19 submissions or approximately $58 \%$ of the respondents.

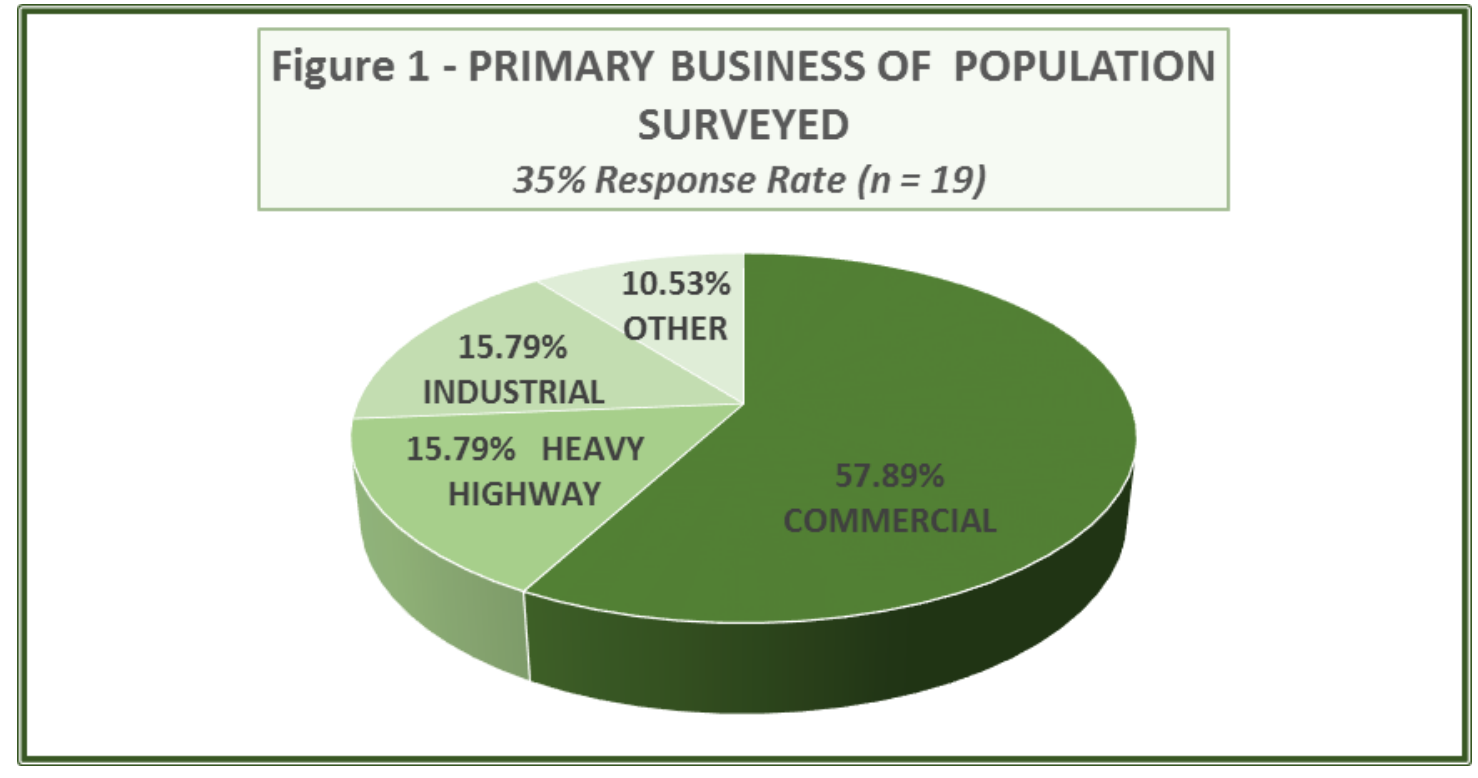

Aside from establishing a profile for survey contributors and to qualify responses, additional survey questions identified software currently being used in industry. Figure 2 identifies current software and their respective distribution of use among the responding population. As shown in the figure, few software packages show wide-spread use among contributing companies. Both OnScreen Takeoff and BlueBeam proved to be the most popular among commercial groups. In fact, in our combined analysis for take-off software most other take-off software packages made only a single appearance. Further investigation revealed that the distribution of companies among the three major categories may have contributed to certain software packages appearing fewer times among the collected responses. With eleven commercial companies responding, the combined results overshadow responses provided by heavy highway and industrial groups. Given that two of the three heavy highway companies that responded use Heavy Bid for construction take-offs, consideration should be given to the impact that a larger heavy highway population could have on the combined outcomes and the resulting software list. It is evident from the collected data that there exists a multitude of software packages available to assist with construction quantity take-offs with few common to all major categories and companies. 


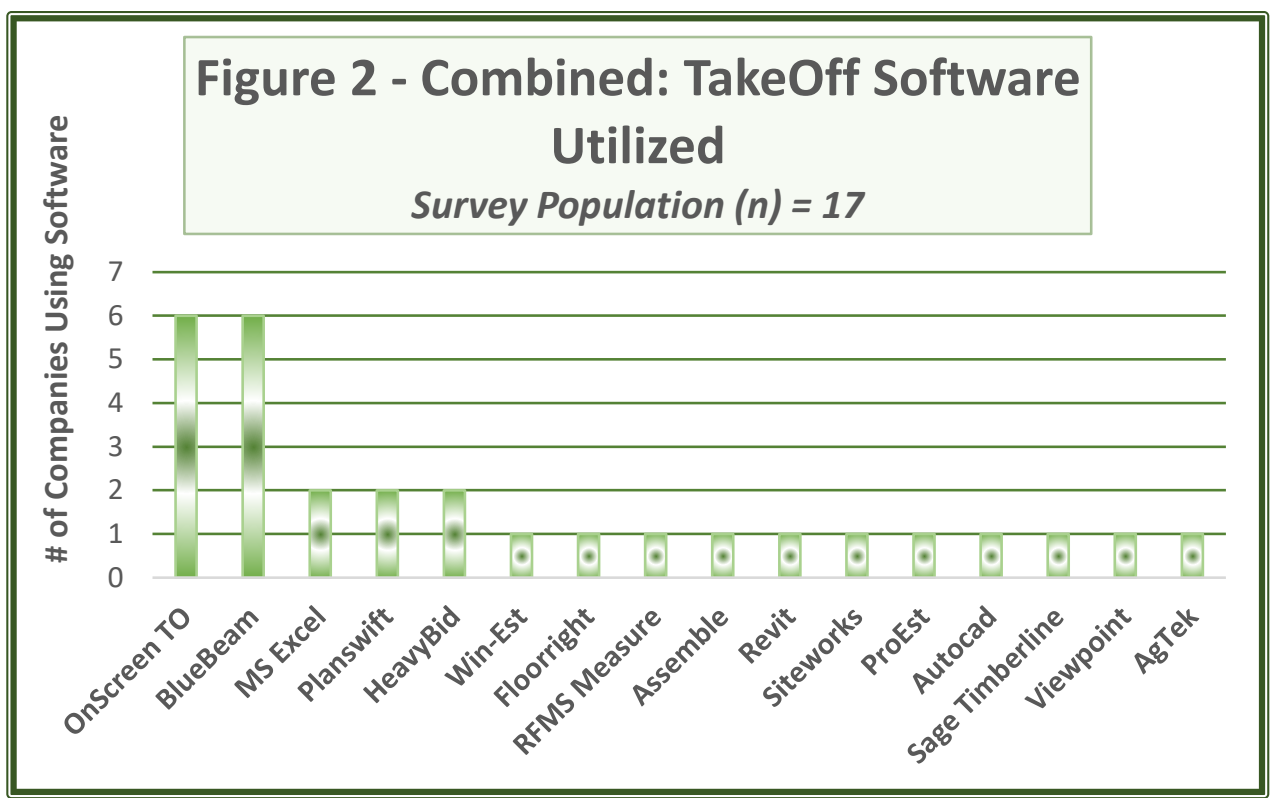

Figure 3 shows the distribution of software use for construction estimating. Though not specific to the construction industry, Microsoft Excel stood out among the software used for cost estimating. Heavy Bid was used by all three heavy highway companies, again exposing the significance of the number of respondents in each of the three major categories. In addition to identifying types of software used and the resulting number of respondents using each software, data was collected in regards to the number of individual software packages used by each respondent.

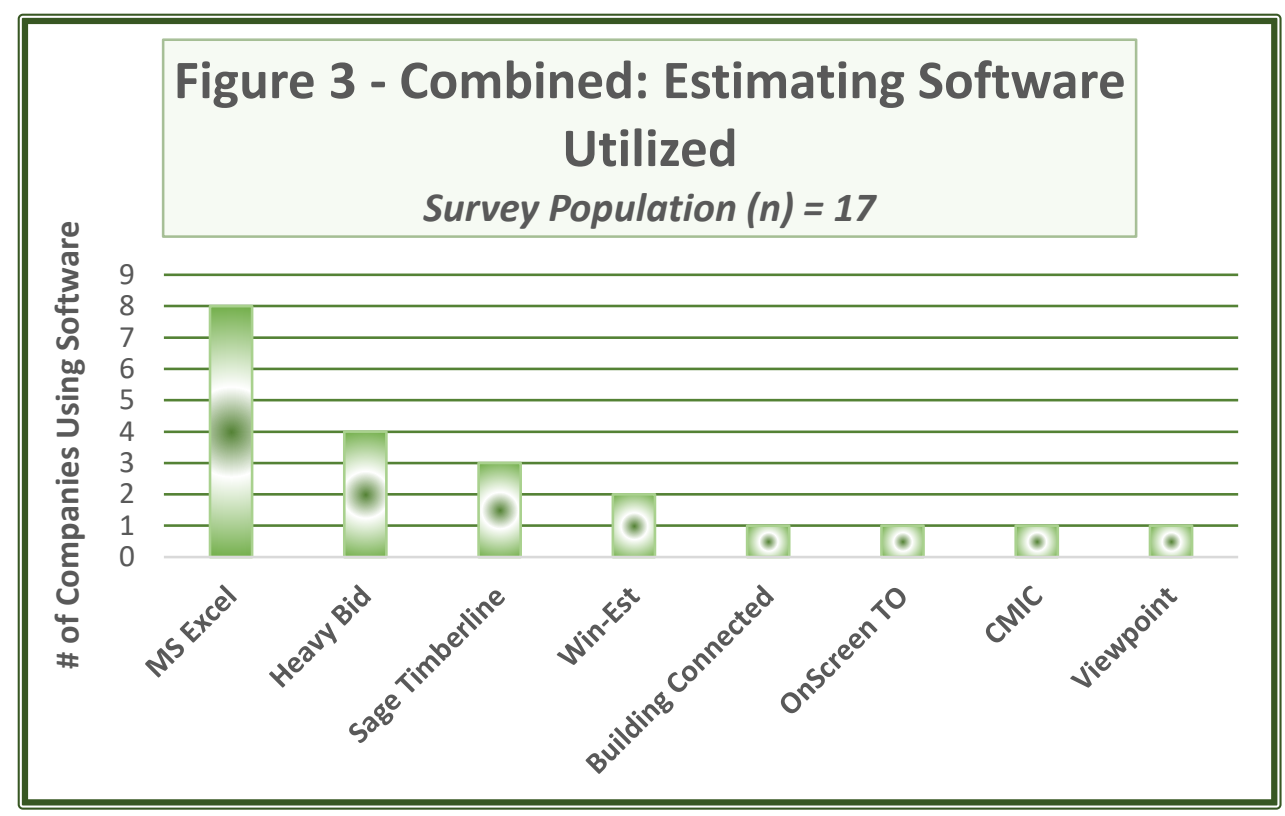


Figures 4 and 5 present the number of take-off software packages and the number of estimating software packages used by each company surveyed. The results revealed that at least half of the companies responding to the survey use multiple software packages for both quantity take-off and cost estimating.
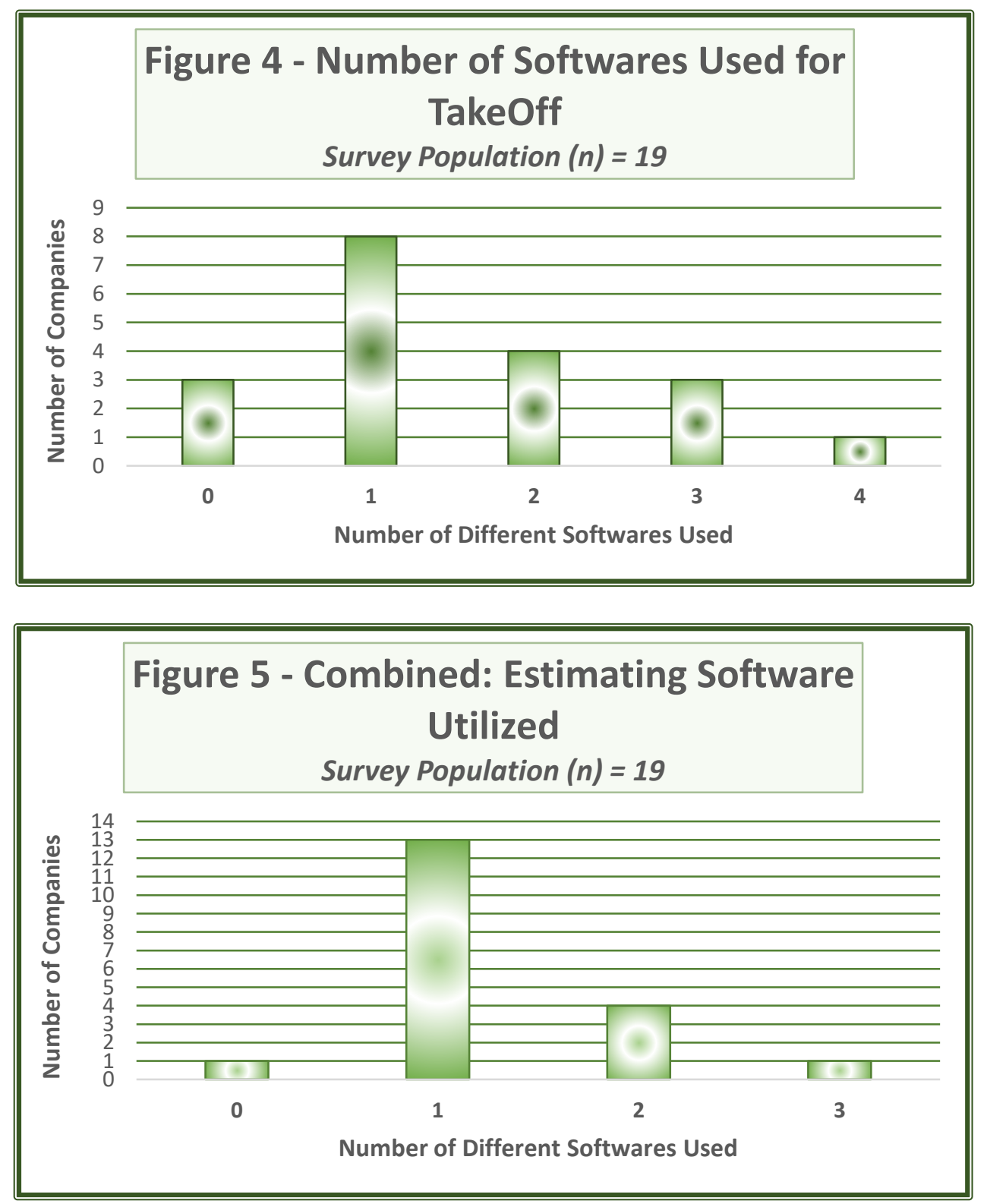

Data was also collected to identify the importance of the selection criteria. Two methods were used. The first method was a "rating outcome" that allowed respondents to assign an importance rating to each criterion. A 4-level (0-3) rating scale was used with $0=$ criterion not satisfied; $1=$ criterion partially satisfied; $2=$ criterion mostly satisfied; and $3=$ criterion fully satisfied. Table 2 presents the Combined Rating Outcomes. The ratings (0-3) allowed users to assign equal importance to multiple criterion -- actually, it required them to do so. The far-right column indicates the number of points earned (out of 57) as a percentage. The top 5 criteria are identified by the bracketed number. "Available Functions" was rated number one, while "Ease 
of Use / Intuitiveness" and "Tech Support Availability / Response Time" were tied for second. "Industry Popularity" was rated the least important.

\begin{tabular}{|c|c|c|c|c|c|c|c|c|c|c|c|c|c|c|c|c|c|c|c|c|c|}
\hline \multirow[b]{3}{*}{$\begin{array}{l}\text { Survey } \\
\text { Respondents }\end{array}$} & \multicolumn{21}{|c|}{ Table 2 Combined Rating Outcomes } \\
\hline & \multicolumn{19}{|c|}{ Rating Scale ( 3-very important, 2 important, 1 somewhat important, 0 not important) } & \multirow{3}{*}{ 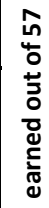 } & \multirow{3}{*}{ 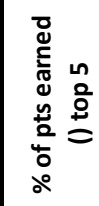 } \\
\hline & 1 & 2 & 3 & 4 & 5 & 6 & 7 & 8 & 9 & 10 & 11 & 12 & 13 & 14 & 15 & 16 & 17 & 18 & 19 & & \\
\hline Factors & & & & & & & & & & & & & & & & & & & & & \\
\hline Cost & 2 & 1 & 2 & 2 & 2 & 1 & 3 & 2 & 3 & 1 & 1 & 1 & 2 & 1 & 1 & 2 & 2 & 0 & 2 & 31 & $54.4 \%$ \\
\hline $\begin{array}{l}\text { Familiarity/ } \\
\text { Navigation }\end{array}$ & 1 & 2 & 1 & 2 & 2 & 1 & 2 & 2 & 3 & 0 & 3 & 3 & 3 & 3 & 2 & 2 & 3 & 3 & 2 & 40 & $70.2 \%(4)$ \\
\hline \begin{tabular}{|l} 
Ease of Use/ \\
Intuitiveness
\end{tabular} & 1 & 3 & 2 & 2 & 3 & 2 & 3 & 1 & 3 & 2 & 3 & 3 & 3 & 3 & 3 & 1 & 3 & 3 & 2 & 46 & $80.7 \%(2)$ \\
\hline $\begin{array}{l}\text { Security/ Data } \\
\text { Protection }\end{array}$ & 0 & 2 & 2 & 3 & 2 & 2 & 2 & 2 & 2 & 2 & 2 & 3 & 1 & 1 & 2 & 2 & 3 & 3 & 2 & 38 & $66.7 \%$ \\
\hline $\begin{array}{l}\text { Compatibility w/ } \\
\text { Other Software }\end{array}$ & 1 & 2 & 2 & 3 & 2 & 1 & 2 & 2 & 2 & 2 & 2 & 3 & 3 & 1 & 2 & 3 & 2 & 2 & 2 & 39 & $68.4 \%(5)$ \\
\hline Industry Popularity & 0 & 3 & 1 & 0 & 1 & 2 & 1 & 0 & 1 & 0 & 3 & 0 & 2 & 2 & 1 & 1 & 1 & 3 & 2 & 24 & $42.1 \%$ \\
\hline $\begin{array}{l}\text { Reputation/ Track } \\
\text { Record }\end{array}$ & 2 & 3 & 2 & 1 & 3 & 2 & 3 & 0 & 1 & 0 & 3 & 2 & 2 & 3 & 2 & 1 & 3 & 3 & 2 & 38 & $66.7 \%$ \\
\hline Available Functions & 2 & 3 & 2 & 2 & 3 & 3 & 3 & 2 & 2 & 3 & 3 & 3 & 2 & 2 & 3 & 1 & 3 & 3 & 2 & 47 & $82.5 \%(1)$ \\
\hline $\begin{array}{l}\text { Tech Support } \\
\text { Availability/ } \\
\text { Response Time }\end{array}$ & 3 & 1 & 2 & 3 & 3 & 3 & 2 & 1 & 3 & 2 & 2 & 2 & 3 & 3 & 2 & 3 & 3 & 3 & 2 & 46 & $80.7 \%(2)$ \\
\hline Available Training & 3 & 1 & 2 & 1 & 2 & 3 & 2 & 1 & 3 & 1 & 2 & 2 & 2 & 1 & 2 & 2 & 3 & 3 & 2 & 38 & $66.7 \%$ \\
\hline $\begin{array}{l}\text { Industry Referrals/ } \\
\text { Recommendations }\end{array}$ & 2 & 3 & 2 & 2 & 2 & 3 & 1 & 1 & 1 & 1 & 3 & 2 & 1 & 0 & 3 & 2 & 3 & 3 & 2 & 37 & $64.9 \%$ \\
\hline
\end{tabular}

The second method "ranked" the criteria, which assigned a unique value (0-11) for each criterion. Ranking requires respondents to choose which criterion is most important with no allowance for equal levels of importance.

Figure 6 displays the criterion ranking based on a percentage of available points earned. Each respondent ranked individual criterion in order from 11 to 1 with 11 being the highest points available. Points for each category were totaled and compared to the maximum possible total of 855 for combined assignable points.

"Available Functions" was rated number one, while "Ease of Use / Intuitiveness" was ranked second. "Industry Popularity" was rated the least important. These were similar results that were found in the rating outcomes, however, ranking did not allow for criterion to be equal. This resulted in greater variance in the middle "rated" and "ranked" criteria, as can be seen in Table 2 and Figure 6, respectively. The ability to combine ranking with rating was a fundamental building block in the creation of the decision matrix, which is described in the following section of this report. 


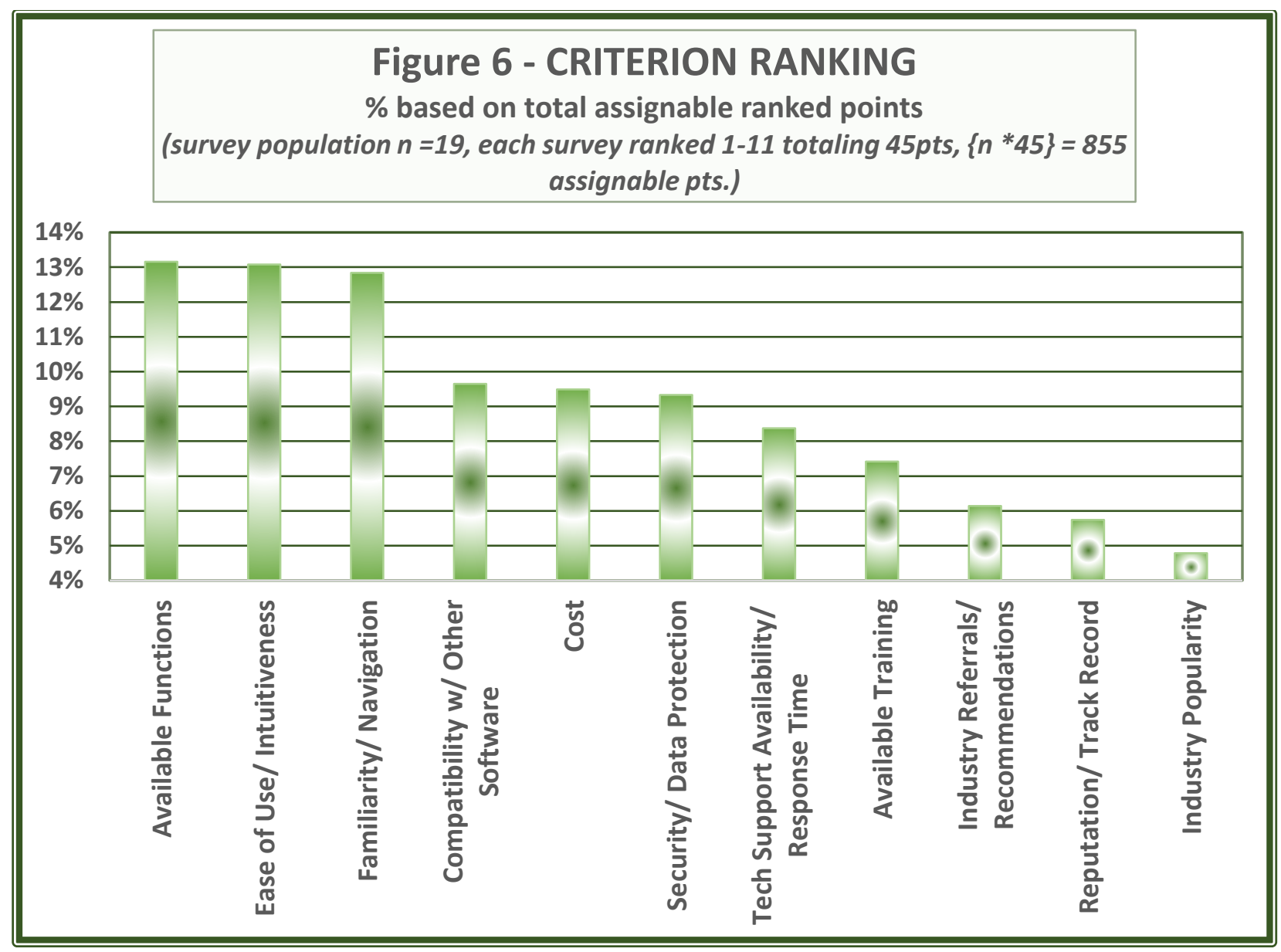

\section{Recommendations and Conclusions}

One of the objectives of this study was to develop a "rating matrix" i.e., a decision-making tool that would assist users in software selection. The concept was to combine the flexibility of the ratings with the objectivity of the rankings. Users must also have the ability to assign a performance rating to each criterion which actually serves as a weighting to determine to what degree each criterion is satisfied.

Based on the data collected, it is evident that the selected criteria have varying degrees of importance that should be determined by the individual or group selecting the software. The results of the survey revealed that all selected criteria had some level of importance and should be integrated into the decision-making process for software selection.

The Software Decision Matrix was designed to allow the users to "weigh" each of the 11 criteria based on their level of importance. The weights can be assigned any value between 0 and 100, as long as the total does not exceed 100 (a warning will appear if the total is not equal 100). In addition, the matrix required a performance rating for each criterion using a $0-3$ scale with $0=$ criterion not satisfied; $1=$ criterion partially satisfied; $2=$ criterion mostly satisfied; and $3=$ criterion fully satisfied. 
The total for each criterion is calculated by multiplying the assigned weight by the designated rating. When comparing software, criteria totals for each software are summed and divided by 300 , the maximum amount of possible points. This total is shown as a percentage which may be easier for most users to interpret than a raw point total. Table 3 displays the Software Decision Matrix which is a fully-functional working tool. Software packages earning a higher percentage of points reveal a more suitable selection based on the user's weights and ratings.

The decision matrix can be used individually or collectively. For example, an individual of a software selection team can use the matrix prior to meeting as a group and then collectively discuss and assign team weights and ratings. The matrix was not designed for a specific type of software and is adaptable to any type of software for any discipline, which expands the use of this tool.

\begin{tabular}{|c|c|c|c|c|c|c|c|c|c|}
\hline \multirow[b]{3}{*}{ Decision Criteria } & \multirow[b]{3}{*}{ Weight } & \multicolumn{8}{|c|}{ Software Reviewed } \\
\hline & & \multicolumn{2}{|c|}{ Software Name } & \multicolumn{2}{|l|}{ Software Name } & \multicolumn{2}{|l|}{ Software Name } & \multicolumn{2}{|l|}{ Software Name } \\
\hline & & $\begin{array}{c}\text { Performance Rating }{ }^{*} \\
\text { Scale 0-3 }\end{array}$ & Total & $\begin{array}{c}\text { Performance Rating Scale } \\
0-3\end{array}$ & Total & $\begin{array}{c}\begin{array}{c}\text { Performance Rating Scale } \\
0-3\end{array} \\
\end{array}$ & Total & \begin{tabular}{|c|} 
Performance Rating Scale \\
$0-3$
\end{tabular} & Total \\
\hline Available Functions & 15 & 2 & 30 & 3 & 45 & & 0 & & 0 \\
\hline Ease of Use/ Intuitiveness & 15 & 2 & 30 & 2 & 30 & & 0 & & 0 \\
\hline Familiarity/ Navigation & 15 & 2 & 30 & 3 & 45 & & 0 & & 0 \\
\hline $\begin{array}{l}\text { Compatibility w/ Other } \\
\text { software }\end{array}$ & 12 & 2 & 24 & 3 & 36 & & 0 & & 0 \\
\hline Cost & 15 & 3 & 45 & 1 & 15 & & 0 & & 0 \\
\hline Security/ Data Protection & 10 & 2 & 20 & 2 & 20 & & 0 & & 0 \\
\hline $\begin{array}{l}\text { Tech Support Availability/ } \\
\text { Response Time }\end{array}$ & 5 & 2 & 10 & 3 & 15 & & 0 & & 0 \\
\hline Available Training & 5 & 3 & 15 & 3 & 15 & & 0 & & 0 \\
\hline \begin{tabular}{|l} 
Industry Referrals/ \\
Recommendations
\end{tabular} & 2 & 2 & 4 & 2 & 4 & & 0 & & 0 \\
\hline Reputation/ Track Record & 5 & 3 & 15 & 3 & 15 & & 0 & & 0 \\
\hline Industry Popularity & 1 & 2 & 2 & 3 & 3 & & 0 & & 0 \\
\hline Total Weighted Points & 100 & Total Score & $75 \%$ & Total Score & $81 \%$ & Total Score & $0 \%$ & Total Score & $0 \%$ \\
\hline
\end{tabular}

- Performance Rating Scale: 3 = fully satisfies; 2 = mostly satisfies ; 1 = partially satisfies; 0 = does not satisfy criterion

The authors of this paper were of the firm belief that they should incorporate industry standards into the curriculum to provide students with tools that the industry currently uses. It is interesting to note that in both the rating outcomes and the ranking outcomes that Industry Popularity, which is a direct reflection of industry use, is ranked last.

The authors hope to expand this study and survey a larger population of the construction industry with respect to other types of software packages, which would include other aspects of construction, such as scheduling, document control, and bidding, to name a few. Since the focus of our academic program is primarily commercial construction, the target audience for our expanded survey would be commercial contractors which may provide more meaningful data to our academic program. The overlying value of this research effort was the development of the decision matrix which is adaptable to a variety of software selection scenarios. 


\section{References}

[1] Software Advice, "Construction Estimating Software," https://www.softwareadvice.com/construction/cost-estimating-softwarecomparison/\#buyers-guide

[2] FrontRunners $®$ for Construction Estimating, November 2017, Gartner Methodology, https://www.softwareadvice.com/construction/cost-estimating-software-comparison/\#topproducts

[3] Why Use Estimating Software?, "Can computer-aided estimating software help your shop make money?," Reprinted From: Manufacturing Engineering - vol. 127 no. 6, http://www.microest.com/articles/Why_Use_Estimating_Software.pdf

[4] J. B. Smithwick, J. J. Mischung, and K. T. Sullivan," Impact of Estimating Software on Student Performance for Simple Quantity Takeoff Calculations," 50th ASC Annual International Conference Proceedings, Associated Schools of Construction 2014, Washington D.C., March 26-28, 2014.

[5] M.S. Bandor, "Quantitative Methods for Software Selection and Evaluation," Tech. rep. CMU/SEI-2006-TN-026, Carnegie Mellon University, 2006.

[6] S. Karshenas, and J. Tse, "A Case-Based Reasoning Approach to Construction Cost Estimating." Proc., Int. Workshop on Information Technology in Civil Engineering 2002, ASCE, Reston, VA, 113-123, 2002.

[7] D. Yang, Q. Wang, M.S. Li, Y. Yang, K. Ye, and J. Du, "A Survey on Software Cost Estimation in the Chinese Software Industry," New York: Assoc. Computing Machinery, 2008.

[8] I. Reinhartz-Berger, A. Sturm, and Y. Wand, "Comparing Functionality of Software Systems: An Ontological Approach," Data \& Knowledge Engineering, vol. 87, pp. 320338, 2013.

[9] K.R. Jayakumar and A. Abran , "A Survey of Software Test Estimation Techniques", Journal of Software Engineering and Applications, Vol, 6, p. 47-52, 2013.

[10] K.J. Moløkken-Østvold, M. Jørgensen, S.S. Tanilkan, H. Gallis, A.C. Lien, and S.E. Hove, "A Survey on Software Estimation in the Norwegian Industry," Proceedings Software Metrics Symposium, 208-219, 2004.

[11] J. Goulding and E. Lou, "E-readiness in Construction: An Incongruous Paradigm of Variables," Architectural Engineering and Design Management, vol. 9, no. 4, p. 265-280, 2013.

[12] J. Snow and M. Mann, "Qualtrics Survey Software: Handbook for Research Professionals," 2013, http://www.qualtrics.com 